08

\title{
Гетероструктуры с квантовыми точками InGaAs/GaAs, легированными атомами переходных элементов. І. Фотолюминесцентные свойства
}

\author{
() М.В. Дорохин, А.В. Здоровейщев, Е.И. Малышева, Ю.А. Данилов \\ Научно-исследовательский физико-технический институт Нижегородского государственного университета \\ им. Н.И. Лобачевского, \\ 603950 Нижний Новгород, Россия \\ e-mail: dorokhin@nifti.unn.ru
}

(Поступило в Редакцию 12 июля 2016 г.)

Исследованы оптические свойства гетероструктур с квантовыми точками InAs/GaAs, легированными атомами марганца или хрома в процессе выращивания методом МОС-гидридной эпитаксии. Комбинированные измерения топографии поверхности и спектров люминесценции показали возможность управления спектральными характеристиками структур за счет изменения условий формирования и размеров квантовых точек в присутствии атомов примеси. Результаты объясняются особенностями формирования нанокластеров InAs на поверхности GaAs в присутствии атомов Mn или $\mathrm{Cr}$.

DOI: 10.21883/JTF.2017.09.44915.1988

\section{Введение}

В течение последних 20 лет светоизлучающие диоды на основе гетероструктур с квантовыми точками (КТ) InAs/GaAs представляют не только фундаментальный научный интерес, но и используются в ряде коммерческих приложений [1-5]. В частности, широко известны работы, описывающие создание лазерных и светоизлучающих диодов на КТ, работающих на длинах волн 1.3-1.55 $\mu \mathrm{m}$, перспективных для волоконно-оптических линий связи $[1,4-6]$. Основными преимуществами структур с КТ являются глубокий ограничивающий потенциал и, в перспективе, узкая линия люминесценции (поскольку спектр одиночной квантовой точки подобен спектру атома).

Наиболее распространенные методы формирования КТ используют явление самоорганизации нанокластеров материала при гетероэпитаксии на полупроводнике с отличающимся параметром решетки $[3,4]$. Достоинством указанного метода является простота, недостатком значительный разброс по размерам КТ в массиве, приводящий к сдвигу энергетических уровней отдельных КТ [7] и обусловливающий сравнительно большую ширину линии люминесценции. Для стабилизации поверхности роста КТ и снижения разброса по размерам применяется легирование различными примесями. Влияние легирования на особенности самоорганизации КТ исследовалось в ряде работ [8-11]. Модификация механизма формирования КТ вносит контролируемые изменения в их свойства. Например, легирование висмутом КТ в процессе роста, выполненное в [8], привело к модификации механизма самоорганизации и формированию массива КТ с меньшей шириной спектральной линии. Легирование атомами Мn, выполненное в [10,11], применяется для придания массиву КТ ферромагнитных свойств.

В первой части работы приведены результаты исследований гетероструктур с KT InAs/GaAs, легирован- ными атомами $\mathrm{Mn}$ или $\mathrm{Cr}$ в процессе формирования КТ. Введение указанных примесей используется для формирования структур спинтроники с целью управления спином носителей заряда в КТ, содержащих примесь $\mathrm{Mn}(\mathrm{Cr})$. Особенностью изготовленных структур по сравнению с [10-12] является применение метода газофазной эпитаксии $[9,13]$. Целями исследования являлись: изучение механизмов формирования КТ в присутствии примеси переходного элемента и поиск путей контролируемого управления свойствами структур с КТ, формируемыми методом МОС-гидридной эпитаксии. Показано, что варьирование концентрации примесей позволяет управлять длиной волны люминесценции исследованных структур и расширять спектральный диапазон в область $0.9-1.3 \mu \mathrm{m}$.

\section{1. Использованные экспериментальные методики}

Структуры были выращены на подложке (100) $n$-GaAs методом газофазной эпитаксии из металлорганических соединений и арсина при атмосферном давлении газаносителя водорода. На первой стадии выращивался буферный слой $n$-GaAs: $\mathrm{Si}$ при температуре $650^{\circ} \mathrm{C}$ и тонкий $(50 \mathrm{~nm})$ слой нелегированного GaAs. Затем температура выращивания снижалась до $520^{\circ} \mathrm{C}$, и на поверхность структур осаждался массив самоорганизованных KT InAs. KT были изготовлены по стандартной методике, описанной в $[9,13,14]$. В процессе выращивания КТ производилось легирование атомами Мn или атомами $\mathrm{Cr}$. Легирование осуществлялось методом распыления $\mathrm{Mn}(\mathrm{Cr})$ мишени импульсным $\mathrm{Nd}$ : YAG-лазером. Концентрация примесей варьировалась путем управления интенсивностью лазерного излучения. Значения концентрации оценивались из сравнения с контрольными структурами, содержащими одиночный дельта-слой $\mathrm{Mn}$ 
Параметры образцов для исследований; $Q_{\mathrm{Mn}(\mathrm{Cr})}-$ номинальное содержание примеси ( $\mathrm{Mn}$ или $\mathrm{Cr}$ )

\begin{tabular}{c|c|l}
\hline Структура & $Q_{\mathrm{Mn}(\mathrm{Cr})}, \mathrm{cm}^{-2}$ & \multicolumn{1}{|c}{$\begin{array}{c}\text { Ожидаемый тип } \\
\text { проводимости }\end{array}$} \\
\hline$A 1$ & $4 \cdot 10^{12}$ & Дырочный $[10,11,13]$ \\
$A 2$ & $8 \cdot 10^{12}$ & Дырочный $[10,11,13]$ \\
$A 3$ & $2 \cdot 10^{13}$ & Дырочный $[10,11,13]$ \\
51 & $2 \cdot 10^{13}$ & Высокоомный $[12]$ \\
52 & $4 \cdot 10^{13}$ & Высокоомный $[12]$ \\
53 & $8 \cdot 10^{13}$ & Высокоомный $[12]$ \\
$K$ & 0 & Неизвестно
\end{tabular}

в GaAs, выращенными в подобных условиях. Согласно оценкам, слоевая концентрация $\mathrm{Mn}$ варьировалась в пределах $4 \cdot 10^{12}-2 \cdot 10^{13} \mathrm{~cm}^{-2}$, слоевая концентрация хрома - в пределах $(2-8) \cdot 10^{13} \mathrm{~cm}^{-2}$. После выращивания КТ на поверхности формировался тонкий $(20 \mathrm{~nm})$ нелегированный покровный слой GaAs. Температура выращивания покровного слоя совпадала с температурой выращивания КТ. Для определенности структуры, содержащие КТ : Мn обозначим как структуры $A$, структуры с КТ : Cr - как структуры Б. Также были сформированы контрольные структуры, не содержащие магнитной примеси в области КТ (структуры $K$ ).

Спектральные особенности структур с КТ исследовались методом спектроскопии фотолюминесценции (ФЛ) при температуре $77 \mathrm{~K}$. ФЛ возбуждалась $\mathrm{He}-\mathrm{Ne}$-лазером мощностью $40 \mathrm{~mW}$. Морфология массива KT InAs, выявленного методом селективного травления покровного слоя $[15,16]$, исследовалась на атомносиловом микроскопе (ACM) NT-MDT Solver Pro. Для этого покровный слой был стравлен в селективном травителе, имеющем скорость травления GaAs $30 \mathrm{~nm} / \mathrm{min}$, a InAs - менее $1 \mathrm{~nm} / \mathrm{min}$. Замедление процесса травления твердого раствора $\operatorname{In}_{x} \mathrm{Ga}_{1-x}$ As проявлялось при $x=0.2$, поэтому при полном стравливании покровного слоя $\mathrm{GaAs}$ выявлялась поверхность ближайшего слоя $\mathrm{In}_{x} \mathrm{Ga}_{1-x} \mathrm{As}$, соответствующая пороговому значению состава $x=0.2$. Указанная методика подробно описана в работе $[15,16]$. Схема образцов для исследований показана на рис. 1, параметры образцов для исследований приведены в таблице.

\section{2. Результаты исследований и обсуждение}

\section{1. Фотолюминесценция и морфология поверхности структур, легированных атомами $\mathrm{Mn}$ (структуры $\boldsymbol{A}$ )}

Спектры фотолюминесценции структур $A$, измеренные при $77 \mathrm{~K}$, показаны на рис. 2. Из всех приведенных спектров была вычтена широкая полоса с максимумом при $\sim 1.2 \mathrm{eV}$, соответствующая ФЛ излучению $n$-GaAs

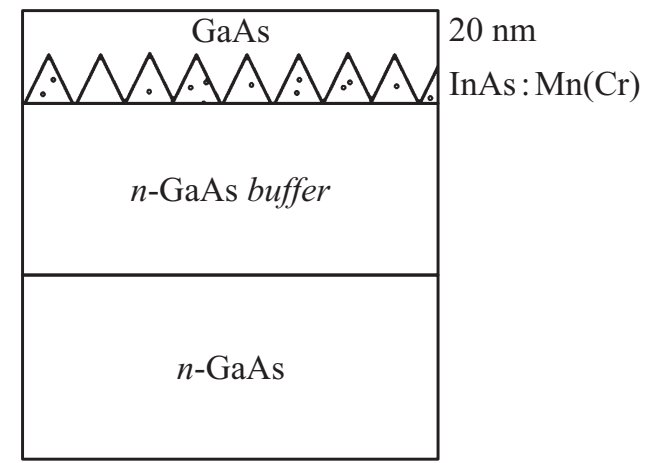

Рис. 1. Схема структур для исследований с КT InAs : Cr и InAs : Mn.

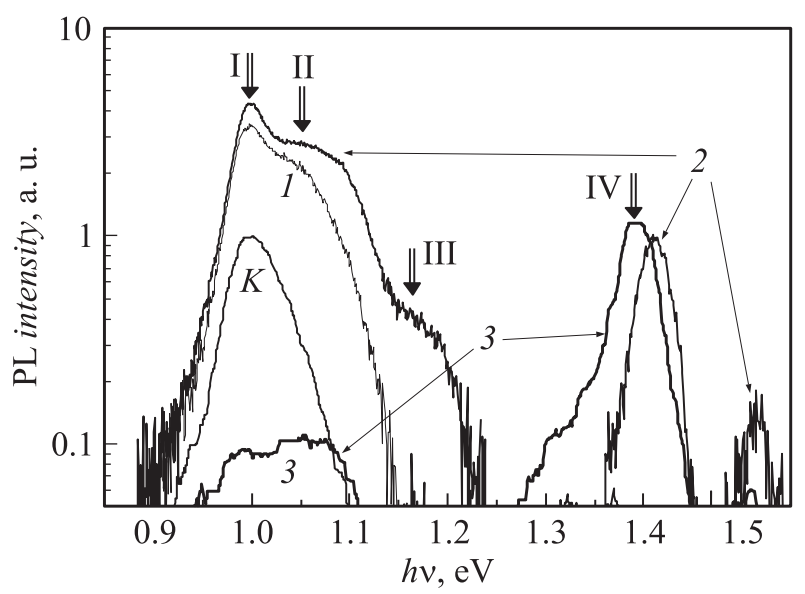

Рис. 2. Спектры фотолюминесценции, измеренные при температуре $77 \mathrm{~K}$, структур с KT InAs : Mn, отличающихся содержанием Mn: кривая $1-4 \cdot 10^{12} \mathrm{~cm}^{-2}$, кривая $2-8 \cdot 10^{12} \mathrm{~cm}^{-2}$, кривая $3-2 \cdot 10^{13} \mathrm{~cm}^{-2}$. Кривая $\mathrm{K}-$ спектр контрольной структуры. Римскими цифрами обозначены присвоенные в тексте номера пиков люминесценции.

подложки. На спектрах ФЛ контрольной нелегированной структуры наблюдается полоса с максимумом при энергии $\approx 1 \mathrm{eV}$, связанная с излучательными переходами между состояниями в КТ (рис. 2 , кривая $K$ ). Согласно предположениям, сделанным в работе [2], полоса обусловлена рекомбинацией в массивах КТ, а ее ширина связана с разбросом КТ по размерам. В результате легирования атомами Mn с минимальной слоевой концентрацией $4 \cdot 10^{12} \mathrm{~cm}^{-2}$ происходит изменение спектра: увеличивается общая интенсивность ФЛ, а также появляется вторая полоса ФЛ (II) с максимумом при энергии $\sim 1.04 \mathrm{eV}$ (рис. 2, кривая 1). Для анализа спектральных линий выполнялись разложения экспериментального спектра на гауссианы. Соотношение интенсивностей второй и первой линий составляет $\sim 0.62 \pm 0.05$. Второй максимум ФЛ может быть обусловлен излучательными переходами в массиве КТ с отличающимися от первого массива размерами. Согласно [15], оба массива могут одновременно присутствовать на спектре даже 

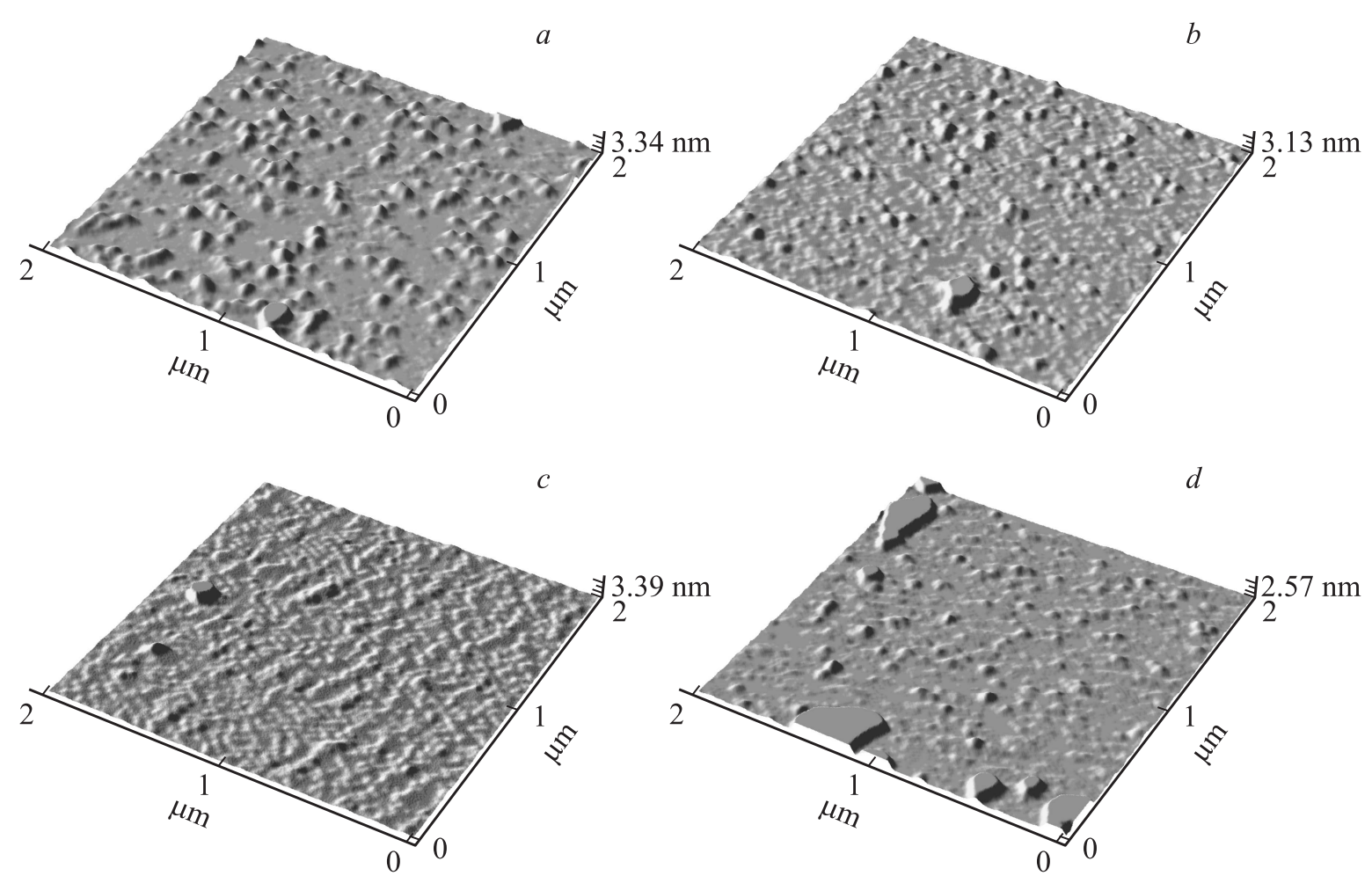

Рис. 3. Морфология поверхности структур с КТ InAs/GaAs: (a) контрольная структура $K$, (b) структура $A 2$ (содержание Мn $\left.8 \cdot 10^{12} \mathrm{~cm}^{-2}\right),(c)$ структура $A 3$ (содержание $\left.\mathrm{Mn} 2 \cdot 10^{13} \mathrm{~cm}^{-2}\right),(d)$ структура $53\left(\right.$ содержание $\left.\mathrm{Cr} 8 \cdot 10^{13} \mathrm{~cm}^{-2}\right)$.

без легирования марганцем. При увеличении содержания $\mathrm{Mn}$ до $8 \cdot 10^{12} \mathrm{~cm}^{-2}$ (рис. 2, кривая 2) имеют место аналогичные тенденции: общая интенсивность ФЛ увеличивается, на спектре появляется третья полоса (III) при $1.16 \mathrm{eV}$ и четвертая (IV) при энергии $\sim 1.4 \mathrm{eV}$. Соотношение интенсивностей второй и первой линий составляет $\sim 0.61 \pm 0.05$ (т.е. не меняется в пределах погрешности). В случае слоевой концентрации $\mathrm{Mn}$, вводимого в область КТ, равной $2 \cdot 10^{13} \mathrm{~cm}^{-2}$, происходит существенное изменение спектров ФЛ структур (рис. 2, кривая 3): интенсивности линий, соответствующих излучательным переходам в массиве КТ, существенно снижаются (ниже уровня контрольной структуры). Наибольшая интенсивность характерна для полосы IV с максимумом при энергии $\sim 1.4 \mathrm{eV}$. Происхождение указанного максимума не может быть интерпретировано однозначно. В указанной области энергий излучают квантовые ямы InGaAs [17], изолированные уровни Mn в $\mathrm{GaAs}[17,18]$, а также смачивающий слой, образующийся при выращивании InAs KT [15]. По-видимому, в рассматриваемом случае излучение обусловлено смачивающим слоем InAs. Можно предположить, что указанный слой имеет высокую неоднородность вследствие диффузии атомов In в GaAs подложку в присутствии Mn, об этом свидетельствует высокое значение ширины линии люминесценции $(37 \mathrm{meV})$. Общая интенсивность ФЛ при этом понижается до уровня нелегированной контрольной структуры. Исследованиям ФЛ можно поставить в соответствие измерения морфологии поверхности визуализированного $[15,16]$ массива КТ (изображения $a-c$ на рис. 3). При исследовании морфологии поверхности контрольной нелегированной структуры на АСМ обнаружен массив КТ со следующими средними параметрами: латеральный размер $\sim 60 \mathrm{~nm}$, поверхностная концентрация $\sim 5 \cdot 10^{9} \mathrm{~cm}^{-2}$, высота $\sim 2.5 \mathrm{~nm}$ (рис. $3, a$ ). По-видимому, наблюдаемые на АСМ-изображении кластеры ответственны за появление наблюдаемой в спектре люминесценции полосы I при $1 \mathrm{eV}$. В структурах, содержащих массив КT InAs, легированных марганцем со слоевой концентрацией $8 \cdot 10^{12} \mathrm{~cm}^{-2}$, средний латеральный размер в массиве визуализированных КТ увеличился и составил $\sim 90 \mathrm{~nm}$ (такое изменение больше погрешности), поверхностная концентрация уменьшилась до $\sim 2 \cdot 10^{9} \mathrm{~cm}^{-2}$, высота уменьшилась до $\sim 2 \mathrm{~nm}$ (рис. $3, b$ ). В структурах, легированных Мn до концентрации $2 \cdot 10^{13} \mathrm{~cm}^{-2}$ (рис. $3, c$ ), массив КТ не обнаружен, а наблюдалась относительно ровная поверхность со средней высотой неровности $\sim 0.5 \mathrm{~nm}$, характерная, например, для визуализированной поверхности квантовой ямы InGaAs.

Результаты исследований топографии и ФЛ могут быть объяснены влиянием атомов Мn на процессы формирования КТ. Наличие атомов Mn на поверхности изменяет термодинамические условия формирования нанокластеров, в частности, поверхностную энергию, длину поверхностной диффузии атомов [13]. В результате 


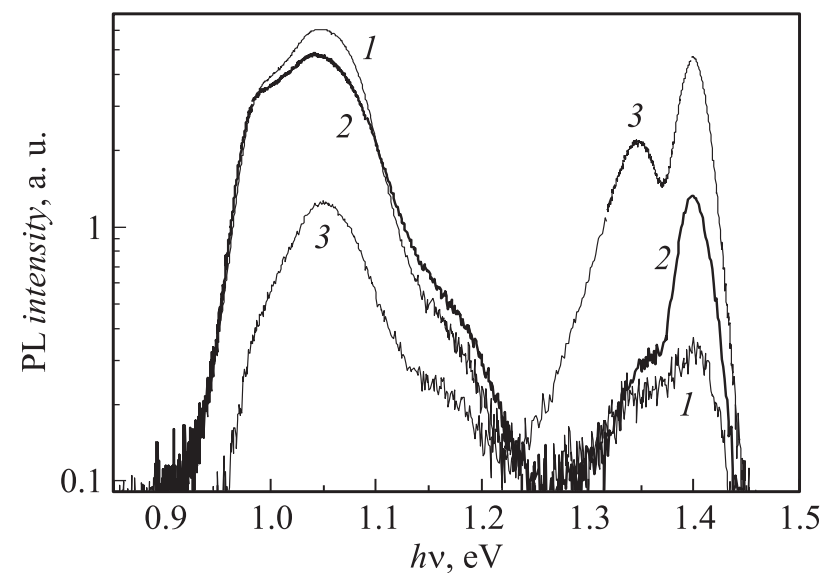

Рис. 4. Спектры фотолюминесценции, измеренные при температуре $77 \mathrm{~K}$, структур с KT InAs : Cr, отличающихся содержанием Cr: кривая $1-2 \cdot 10^{13} \mathrm{~cm}^{-2}$, кривая $2-4 \cdot 10^{13} \mathrm{~cm}^{-2}$, кривая $3-8 \cdot 10^{13} \mathrm{~cm}^{-2}$.

этого изменяется функция равновесного распределения нанокластеров по размерам. Для контрольной структуры эта функция может быть описана кривой Гаусса с максимумом, соответствующим среднему размеру КТ в массиве. Введение $\mathrm{Mn}$ приводит к изменению параметров функции Гаусса (среднего размера и ширины распределения). В результате происходят модификации спектров ФЛ (рис. 2): появление дополнительных линий, связанных с излучательными переходами в кластерах с другими равновесными размерами (эти кластеры наблюдаются на АСМ-изображении, рис. $3, b$ ).

При содержании марганца, равном $2 \cdot 10^{13} \mathrm{~cm}^{-2}$, нанокластеры, ответственные за люминесценцию в диапазоне $1-1.3 \mathrm{eV}$, по-видимому, имеют низкую поверхностную концентрацию (ниже $5 \cdot 10^{8} \mathrm{~cm}^{-2}$ ), при которой становится затруднительной идентификация КТ на АСМ-изображении, однако на спектрах ФЛ пики, которые ассоциируются с этими нанокластерами, зарегистрированы (рис. 2, кривая 3). Помимо изменения термодинамики формирования нанокластеров важную роль играет ускорение диффузионного перемешивания In из InAs и $\mathrm{Ga}$ из подложки в присутствии на поверхности атомов $\mathrm{Mn}[13,18]$. Взаимная диффузия приводит к формированию нанокластеров переменного состава ( $\mathrm{InGaAs})$, излучающих на меньшей по сравнению с нелегированными структурами длине волны. „Голубое“ смещение линий люминесценции КТ в результате введения атомов Мn в процессе выращивания отмечалось в $[19,20]$. Если принять во внимание процессы взаимной диффузии атомов In и $\mathrm{Ga}$, линию при энергии $1.4 \mathrm{eV}$, наблюдаемую в спектре структур с содержанием $\mathrm{Mn} 8 \cdot 10^{12} \mathrm{~cm}^{-2}$ и $2 \cdot 10^{13} \mathrm{~cm}^{-2}$, можно отнести к люминесценции в слое твердого раствора $\operatorname{In}_{x} \mathrm{Ga}_{1-x}$ As переменного состава с размытой гетерограницей. Например, формирование двумерного слоя $\operatorname{In}_{x} \mathrm{Ga}_{1-x} \mathrm{As}$ в результате диффузии обсуждалось для структур с КТ (идентичных контроль- ным), подвергнутых высокотемпературному отжигу [21] при $600^{\circ} \mathrm{C}$ в течение $30 \mathrm{~min}$.

Интересным результатом представляется наличие во всех структурах КТ, ответственных за излучение при $1 \mathrm{eV}$ (об этом свидетельствует точное совпадение энергии соответствующей линии для разных структур). Можно сделать вывод, что формирование InAs KT с размерами $60 / 2.5 \mathrm{~nm}$ термодинамически выгодно даже в присутствии марганца. Увеличение интенсивности ФЛ линии при $1 \mathrm{eV}$ связано с общим повышением интенсивности ФЛ в присутствии атомов Mn. Указанный результат принципиально отличает исследованные структуры от аналогов на основе квантовых ям. Введение атомов Мn в область квантовых ям с концентрацией выше 0.05 at.\% приводит к полному гашению фотолюминесценции вследствие увеличения скорости безызлучательной рекомбинации с участием примесных уровней Mn [22]. Предположительно, в случае введения атомов Мn в структуры с КТ существенного повышения вероятности безызлучательной рекомбинации не происходит. Это может быть обусловлено тем, что энергия дырки, локализованной в КТ, расположена ниже примесного уровня Mn в GaAs, что делает неэффективным при низких температурах механизм безызлучательной рекомбинации в КТ с участием уровней $\mathrm{Mn}$ (для этого потребовался бы термический заброс дырки с состояния в КТ на уровень Mn). Общее повышение интенсивности связывается с увеличением концентрации дырок в результате введения марганца $[10,11]$, поскольку известно, что скорость излучательной рекомбинации пропорциональна концентрации свободных носителей заряда [23].

\section{2. Фотолюминесценция и морфология поверхности структур, легированных атомами $\mathrm{Cr}$ (структуры $Б$ )}

На спектрах фотолюминесценции структур 5 (рис. 4) наблюдаются пики, связанные с излучательными переходами между состояниями в КТ. Аналогично структуре, легированной атомами Mn, на графиках наблюдается две линии ФЛ при энергиях $\sim 1 \mathrm{eV}$ и $1.05 \mathrm{eV}$. В результате легирования атомами хрома спектр ФЛ структур модифицируется, как показано на рис. 4 .

а.Существенно повышается интенсивность второго пика по сравнению с первым. При легировании $\mathrm{Cr}$ со слоевой концентрацией $2 \cdot 10^{13}, 4 \cdot 10^{13}, 8 \cdot 10^{13} \mathrm{~cm}^{-2}$ это соотношение изменяется до $1.5,1.45$ и 2.1 соответственно (кривые 1,2 и 3 соответственно).

б.На спектре появляется два пика при энергиях $\sim 1.35$ и $\sim 1.40 \mathrm{eV}$. Интенсивность указанных пиков увеличивается с увеличением концентрации $\mathrm{Cr}$ в 22 раза. Отношение интенсивностей первого и четвертого пиков в ряду образцов $51-Б 3$ изменяется как $12.1-2.8-0.13$.

в. По сравнению с контрольной структурой интегральная интенсивность ФЛ КТ, легированных $\mathrm{Cr}$, увеличивается. С увеличением содержания $\mathrm{Cr}$ интегральная интенсивность меняется как 8.9-8.3-5.4. 
г. При исследовании на АСМ морфологии поверхности визуализированного массива КT InAs : $\mathrm{Cr}$ со слоевой концентрацией $8 \cdot 10^{13} \mathrm{~cm}^{-2}$ средние размеры КТ не изменились по сравнению с нелегированной контрольной структурой, а поверхностная концентрация уменьшилась до $\approx 2 \cdot 10^{9} \mathrm{~cm}^{-2}$ (рис. $3, d$ ).

На основании полученных результатов можно сделать вывод, что наличие атомов $\mathrm{Cr}$ на поверхности так же, как и наличие марганца, изменяет термодинамические условия формирования нанокластеров. В случае $\mathrm{Cr}$ это приводит к изменению функции распределения по размерам. Так, увеличение интенсивности второго пика ФЛ относительно первого, по-видимому, связано с перераспределением концентрации КТ с разными размерами. При этом, как показывают данные АCM, с увеличением содержания $\mathrm{Cr}$ уменьшается общая концентрация КТ (и относительная интенсивность ФЛ линий от квантовых точек, как показано на рис. 4).

Пик люминесценции при энергии $1.4 \mathrm{eV}$, появляющийся на спектрах структур с КТ : Cr, по-видимому, обусловлен излучательными переходами в смачивающем слое КТ. Появление его на спектре может быть обусловлено увеличением вероятности излучательной рекомбинации с участием энергетических уровней смачивающего слоя на тех участках поверхности, на которых не сформировались КТ. Пик люминесценции при $1.35 \mathrm{eV}$ может быть связан с массивом КТ небольшого размера, которые не визуализируются при травлении покровного слоя. По мере увеличения содержания вводимого хрома увеличивается плотность мелких КТ, что сопровождается увеличением соответствующей линии люминесценции. Также отметим, что энергии 1.35 и $1.40 \mathrm{eV}$ соответствуют рекомбинационным переходам с участием дефектных центров в GaAs [24].

Важным экспериментальным фактом является сохранение и некоторое увеличение интенсивности ФЛ в результате введения Сr. Атомы хрома в полупроводниках $A^{3} B^{5}$ являются глубокими центрами безызлучательной рекомбинации, их введение, как правило, приводит к гашению люминесценции. Но в случае исследованных структур с КТ существенного гашения люминесценции КТ выявлено не было (за исключением структуры с наибольшим содержанием хрома).

\section{Заключение}

В работе проведено легирование КT InAs/GaAs атомами марганца или хрома в процессе выращивания. Показано, что введение примеси переходных элементов позволяет управлять спектральными характеристиками люминесценции структур с КТ: увеличивать ширину спектрального диапазона и варьировать длину волны излучения. При этом влияние атомов $\mathrm{Mn}(\mathrm{Cr})$ на спектры ФЛ InAs/GaAs KТ проявляется в появлении на спектре ФЛ высокоэнергетических линий, интенсивности которых повышаются с увеличением концентрации. Низко- энергетические линии (характерные для нелегированных КТ) либо сохраняются с уменьшением относительной интенсивности (в зависимости от типа и концентрации примеси), либо пропадают из спектра. Изменения спектров, предположительно, обусловлены варьированием равновесных условий формирования нанокластеров, приводящим к изменению их размеров. Таким образом, введение примеси $\mathrm{Mn}$ или $\mathrm{Cr}$ вносит дополнительную степень свободы в технологическом управлении длиной волны излучения структур с КТ, сформированными методом МОС-гидридной эпитаксии.

Авторы выражают благодарность Б.Н. Звонкову за формирование образцов для исследований.

Работа выполнена в рамках реализации государственного задания (проект № 8.1751.2017/ПЧ) Министерства образования и науки России, при поддержке РФФИ (гранты № 15-02-07824, 15-38-20642мол_а_вед и 16-07-01102), а также гранта Президента РФ (МК8221.2016.2).

\section{Список литературы}

[1] Bimberg D., Ribbat C. Microelectronics J. 2003. Vol. 34. N 5-8. P. 323-328.

[2] Алферов Ж.И.. ФТП. 1998. Т. 32. Вып. 1. С. 3-18.

[3] Леденцов Н.Н., Устинов В.М., Щукин В.А., Копьев П.С., Алферов Ж.И., Бимберг Д. ФТП. 1998. Т. 32. Вып. 4. C. 385-410.

[4] Bimberg D., Grundmann M., Ledentsov N.N. Quantum Dot Heterostructures. Chichester: Wiley, 1999. P. 338.

[5] Жуков А.Е., Воловик Б.В., Михрин С.С., Малеев Н.А., Цачульников А.Ф., Никитина Е.В., Каяндер И.Н., Устинов В.М., Леденцов Н.Н. Письма в ЖТФ. 2001. Т. 27. Вып. 17. C. 51-56.

[6] Huffaker D.L., Deppe D.G. Appl. Phys. Lett. 1998. Vol. 73. N 4. P. $520-522$.

[7] Zubkov V.I., Kapteyn C.M.A., Solomonov A.V., Bimberg D. J. Physics: Condens. Matter. 2005. Vol. 17. P. 2435.

[8] Zvonkov B.N., Karpovich I.A., Baidus N.V., Filatov D.O., Morozov S.V., Gushina Yu.Yu. Nanotechnology. 2000. Vol. 11. N 4. P. 221-226.

[9] Звонков Б.Н., Вихрова О.В., Данилов Ю.А, Демидов Е.С., Демина П.Б., Дорохин М.В., Дроздов Ю.Н., Подольский В.В., Сапожников М.В. Оптич. журн. 2008. Т. 75. Вып. 6. С. 56-61.

[10] Holub M., Chakrabarti S., Fathpour S., Bhattacharya P., Lei Y., Ghosh S. Appl. Phys. Lett. 2004. Vol. 85. N 6. P. 973 1036.

[11] Буравлев А.Д., Неведомский В.Н., Убыйвовк Е.В., Сапега В.Ф., Хребтов А.И., Самсоненко Ю.Б., Цырлин Г.Э., Устинов В.М. ФТП. 2013. Т. 47. Вып. 8. Р. 1033.

[12] Meng H.J., Lu J., Chen L., Xu P.F., Deng J.J., Zhao J.H. Phys. Lett. A. 2009. Vol. 373. N 15. P. 1379-1382.

[13] Дорохин М.В., Здоровейщев А.В., Мальшева Е.И., Данилов Ю.А., Звонков Б.Н., Шолина А.Е. Поверхность. Рентгеновские, синхронные и нейтронные исследования. 2012. Вып. 6. С. 55-58.

[14] Karpovich I.A., Baidus N.V., Zvonkov B.N., Morozov S.V., Filatov D.O., Zdoroveishev A.V. Nanotechnology. 2001. Vol. 12. N 4. P. 425-429. 
[15] Karpovich I.A., Zdoroveishev A.V., Gorshkov A.P., Filatov D.O., Skvortsov R.N. // Phys. Low-Dim. Struct. 2003. Vol. 3/4. P. 191.

[16] Автореф. канд. дис. Влияние физико-химической модификации покровного слоя на морфологию и фотоэлектронные спектры квантовых точек InAs/GaAs, выращенных газофазной эпитаксией: А.В. Здоровейщев. Н.Новгород. 2006. $22 \mathrm{c}$.

[17] Zaitsev S.V., Kulakovskii V.D., Dorokhin M.V., Danilov Yu.A., Demina P.B., Sapozhnikov M.V., Vikhrova O.V., Zvonkov B.N. // Physica E. 2009. Vol. 41. N 4. P. 652-654.

[18] Dorokhin M.V., Zvonkov B.N., Danilov Yu.A., Podolskii V.V., Demina P.B., Vikhrova O.V., Malysheva E.I., Sapozhnikov M.V. Int. J. Nanoscience. 2007. Vol. 6. N 3-4. P. 221-224.

[19] Zhou Y.K., Asahi H., Asakura J., Okumura S., Asami K., Gonda S. J. Cryst. Growth. 2000. Vol. 221. N 1-4. P. 605610.

[20] Nagahara S., Tsukamoto S., Arakawa Y. J. Cryst. Growth. 2007. Vol. 301-302. P. 797-800.

[21] Здоровейщев А.В., Дорохин М.В., Мальшева Е.И., Демина П.Б. Инновационные технологии / Под ред. проф. С.В. Булярского. Ульяновск: УлГУ, 2010. № 3. С. 84.

[22] Poggio M., Myers R.C., Stern N.P., Gossard A.C., Awschalom D.D. Phys. Rev. B. 2005. Vol. 72. P. 235313.

[23] Шуберт Ф.Е. Светодиоды / М.: Физматлит, 2008. 496 с.

[24] Pavesi L., Guzzi M. // J. Appl. Phys. 1994. Vol. 75. N 10. P. 4779-4842. 